\title{
8
}

\section{When Access is Restricted: craftiness and combining methods in the study of a secretive elite}

Julie Gervais

CRPS-CESSP (CNRS)

University Paris 1, Panthéon-Sorbonne

"No battle plan ever survives contact with the enemy"

Helmut von Moltke

\section{The puzzle: studying an exclusive and dispersed elite}

How to get access to people in order to carry out proper fieldwork is a common concern in the engine room of research projects integrating sociological dimensions. The access problem appears very tricky when the targeted people hold strategic or prestigious professional positions. And it is even more thorny in the case of members of informal clubs, groups, or institutions that are hard to grasp. This is the case, for example, with French high civil servants who belong to informal networks, the grands corps, that are usually described as a mix of a club, a network, a family, or a mafia (Kosciusko-Morizet, 1973).

In France, all of the top civil servants are traditionally divided into grands corps, whose members share the same careers, the same prestige, or the same professional culture. Thus the French civil service neither constitutes a unified group nor an 
integrated elite. Instead, it is divided into approximately 1,800 corps, each with its own educational entry requirements and its own set of hierarchically-arranged posts. Corps are public bodies, created by decree to organize the careers of specific civil service jobs. There is, for example, a corps for prefects, university professors, and police officers. A corps establishes civil servants' specific terms and conditions (statut) within the overall framework of civil service law, which guarantees security of employment. There is a well-understand hierarchy across and within corps in terms of professional functions, positions, and salaries.

Therefore corps are real sociological entities with their own traditions, beliefs, and values, which stem from a long history (e.g., the corps of roads and bridges was created in 1716 and remained even after the French Revolution), and shared training in a very prestigious and competitive entrance grande Ecole (administrative grands corps come from the Ecole nationale d'administration (ENA) and the grands corps of engineers from the Ecole Polytechnique). They benefit from a long-lasting corporate solidarity which is supported by specific and more or less formal networks such as corporate associations, private clubs, and professional connections. They also hold regular meetings in order to help their members in their career and to sort out collective strategies to increase their influence within and outside the public sector. There is an important mutual aid and automatic solidarity on the sole basis of a shared membership. For example, whenever a member of a grand corps quits a position within a ministry, s/he will try to make sure that her/his successor belong to her/his corps (Suleiman, 1978). Thoroughly analyzed in the literature, this corporate solidarity and the different informal means, relations and groups through which members of grands corps interact remain very secretive and exclusive. French mandarins form a closed elite known to be resistant to objectivization and distrustful towards strangers, which makes it difficult for the observer to carry out sociological research based on first-hand material and empirical fieldwork.

Access to French high civil servants is also problematic because of the difficulty one encounters in locating them. The appellation grands corps refers to a group of high civil servants working in diverse positions and locations. There is no clear institutional entry for the researcher to access members of a grand corps. Some of them work in cabinets, others in agencies, in decentralized departments, in ministries, in local governments, in universities, in private companies and so on. In other words, the corps itself cannot be found. Thus the researcher must get round this methodological difficulty and use cunning in order to give 'sociological flesh' to such an entity.

Methodological issues become even more problematic when one is interested in the French high civil servants' participation in administrative reforms and their possible influence on their shaping and design. Indeed, the very idea of their possible leverage contradicts in particular the French conception of "the public interest", which is meant to transcend vested interests and can only be guaranteed by dedicated civil servants who are supposed to promote an impartial conception of public action based on a monopoly of technical expertise. But if one considers the act of governing as a process which involves a plurality of actors and groups of agents interacting with one another and related by complex interdependence chains (Elias, 1978), the part played by these people appears to be potentially critical and should therefore deserve a central position. Some empirical research has indeed acknowledged the 
fact that right beside the elected politicians, top civil servants (but not only them; see Page, 2003) participate heavily in the governing process by advising political executives and shaping laws and reforms. If this trend can be found in different states and over different periods, it is particularly relevant in the case of France, where most administrative reforms remain profoundly shaped by the strategies and perceptions that stem from the diverse interests of its bureaucrats ${ }^{1}$.

This chapter focuses on the methodological difficulties I had to overcome while studying to what extent administrative reforms known as 'new public management' (NPM), which were designed and implemented by members of grands corps claiming their attempt to roll back the state, were shaped in order to senior civil servants back in. By analyzing 'reflexive changes' (Lowi, 1985) such as administrative mergers and personal reforms, I have shown that their leverage on administrative reforms has led to the spreading of managerial language within public administration and, at the same time, to the reinforcement of existing and traditional institutional arrangements, usually criticized by 'management gurus' (Osborne and Gaebler, 1992). In other words, I have shown how NPM was spread and incorporated by high civil servants and has provided arguments for a 'modernization' aimed at reinforcing their own positions, influence and power (Gervais, 2010, 2011). This chapter analyzes the inner workings of my experience in solving access problems regarding such a closed group.

\section{The alternatives: defects, blind spots and limits}

One way to assess high civil servants' part in an administrative reform is to use direct and participant observation in order to track the reform process accurately and to analyze their actions at different steps, their interactions with politicians, their room for maneuver, the overlap of private and public roles and interests, the way in which they mobilize to defend their collective interests, and so forth. Nevertheless, the high political content of such reforms, the uncertainties attendant on the process, and the sensitive issues which are often at stake make it very difficult for the researcher to obtain authorization to act as a direct observer of administrative life. Enrolling on a vocational training course remains a very good means to penetrate such a network but the closed-circuit procedures, the compartmentalization, and the secretive opaqueness of administrative machinery at this level of decision impede a full appreciation of its functioning through simple observation.

Conducting interviews is quite a widespread technique among public administration scholars. Asking for interview appointments is indeed a good means to get in touch with bureaucrats and find individuals behind institutions. Meeting them in such a context is often very helpful to win their trust and gain access to private archives. It

\footnotetext{
${ }^{1}$ This general assertion should, of course, be tackled in regard to the specificity of the type of reform concerned, the issues at stake, the ministries involved, and so forth. But there seems to be general agreement among comparative public administration scholars upon the important part played by civil servants in the policy making process (Aberbach, Putnam and Rockman, 1981; Page and Wright, 1999 and 2007). Among the factors which substantiate this standpoint the specificity of French high civil service is often mentioned.
} 
can be a good way to get a first overall view of a department, a cabinet, or a ministry, especially during the exploratory stage of a research project. Interviews may also enable the researcher to go beyond the mere collection of official information. Once a trustful relationship is established, they are very useful to locate the different participants in a reform, to find one's way around the institutions involved, to spot the points of tension, and to get a clearer idea of the underlying debates. Nonetheless, used on its own, this methodological tool has some inconveniences.

The case has been made on the methodological difficulties linked to the high social and professional position of the interviewees. Not only will the researcher have to get round secretaries and other doorkeepers, be perfectly presentable, and face intimidatory tactics during the interview, but s/he will also have to make the most out of an interaction which will most of the time be controlled by the person in a power position (Chamboredon et al., 1994; Pinçon and Pinçon-Charlot, 1991). There are other challenges that are more rarely underlined in the literature. Firstly, it is difficult to get in touch with the most relevant actors. The most involved and wellinformed participants in an administrative reform are usually not the most visible or even those apparently responsible according to the formal organizational structure. As shown by Edward Page and Bill Jenkins in the law-making process, the bureaucrats who actually shape reforms may have a lower position on the hierarchical scale and usually know more about the technical aspects than their superiors (Page and Jenkins, 2005). Yet technical issues may actually have an impact on the very content of the reform (or the law in Page's case; Page, 2003). If Page focuses on distinctions between middle-ranking bureaucrats and top civil servants, the same kind of distinction exists within the high civil service or even within one grand corps. The category "high civil servants" is but a generic label tending to conceal a division of labour that I have seen at work. The "petites mains" of the reform master details, hold information, and have technical expertise not wielded by other more publicly visible bureaucrats who will get involved with politicians following briefings by the former. Moreover, the very position of these bureaucrats could make it difficult for them to speak freely and the researcher may have to face the French bureaucrats' much-touted devoir de réserve ${ }^{2}$, especially when the contemporariness of a reform makes the discussion sensitive.

In addition to these methodological issues, focusing on interviews in order to collect primary data may make it more difficult for the researcher to maintain critical distance from subjects' perceptions and lead him/her to adopt too uncritically the subjective perspective of the interviewees on both events and themselves. It may also mislead the observer by lessening the effects of harmonization after the event and give too much value to the weight of ideas (Bongrand and Laborier, 2005). Furthermore, the researcher has to face chronological approximations and time gaps in the interviewees' responses which make it difficult to reconstruct the reform process in an accurate way.

As far as archives are concerned, they constitute a major asset for the researcher to figure out the different steps that the actors underwent and to obtain relevant and

\footnotetext{
${ }^{2}$ According to this devoir de réserve based on complex legal precedents, French civil servants have the duty to show discretion (in their discourse and behaviour) as far as their political opinion and professional activities are concerned.
} 
fairly reliable information on the people who were actually involved, the decisions they made, and the exact pace and chronology of the reform process. However, archives also have their drawbacks insofar as they convey an institutional point of view and make the researcher reliant on managerial tropism and la pensée d'Etat the official discourse coming from "the State" (Bourdieu, 1993, 2012). They use an 'administratively correct' language, with unofficial or vivid sentiments translated in an acceptable form. They do not usually re-transcribe debates and give no insight into the conflicts which may have happened during the meetings concerned. The researcher is left with the mere decisions recorded in the summary of conclusions. Archives highlight official meetings and leave in the dark more informal appointments, they conceal events which may take place between two meetings, and give no insight into possible compromises, negotiations and talks, which sometimes change the balance of power and the content of decisions. They can, moreover, be written in a very elliptical, allusive, and ambiguous language which makes it difficult for someone who did not attend the meeting to understand what was at stake then or what people were arguing about.

\section{A solution: using mixed methods and methodology by induction}

By and large, direct or participant observation, interviews and archives appear to be very useful but have several drawbacks. In my own research, I gambled that these difficulties could be overcome by combining these methodological tools and by using specific data in order to make up for access difficulties. I would now like to go back over my research modus operandi and explain how I carried out my fieldwork on French top-ranking bureaucrats and New Public Management reforms. I used a plurality of sources, an array of methods, and different enquiry techniques, building my methodological equipment as I went along. Thus I began by undertaking exploratory and open-ended interviews, deepened by semi-structured interviews and the collection of written documents, along with direct observations partly carried out by immersion inside the social world studied. If it is tempting to rationalize after the event, most of these methodological 'choices' were the results of availability and access constraints, fiddling combined with chance, coincidences and opportunities (on the role of chance in research see Becker, 1998). If this way of carrying fieldwork may be seen as subjective empirical DIY by researchers generally involved in deductive methodological approaches, I claim an academic conversation should be developed on a specific and rigorous way of figuring out methodology by induction. I would like to focus on four main points in the following section. The first three tackle the technique of interviews and its combination with both direct observation and archives. I will deal with interviews which can bring to light information and data quite close to observation situations, as well as with the inconveniences of direct observation for undertaking rigorous interviews, and I will then describe a specific type of interview which I have been leading, viz interviews on archives'. The last point I will tackle is related to the types of written documents that can be useful in order to analyse a reform process when direct observation is not possible.

A large part of my oral sources consisted of the 117 interviews I undertook for this research project. I made sure that each of these interviews would take place during a relatively long period of time, wagering that it was an important element in order to 
establish trust, to overcome apprehensions, to engage in a more frank dialogue, and thus to try and avoid waffle and political doublespeak. The shortest interview lasted 45 minutes and the longest 6 hours $^{3}$. I have distinguished and characterized the three types of interviews I carried out as follows: i) 'historical interviews', which aimed to collect information about past events from people who either witnessed them or played a part in them; ii) 'contemporary interviews' with the ongoing reform process under examination; and iii) what one might call 'longitudinal' interviews with people who could give insight on both historical and contemporary events and processes. I conducted these interviews in the following three ways: i) classical semistructured interviews, ii) 'interviews in a conversational mode'; and iii) what I have called 'interviews on archives'. I did not resort to a standardized interview pattern and the questions I asked were each time adapted to the person I was speaking to, but the framework dealt with common themes aimed at reconstructing the reforms' genesis, locating the part played by different bureaucrats, identifying their interactions with politicians, and spotting their representations of public service and the role of the state in what they call 'the managerial age'. Interviews usually took place in the same way, beginning with a general interview briefing regarding high civil servants' personal experience of the reform and ending with more individual questions on their social background and their career path ${ }^{4}$.

\section{'De-ritualising' the interview situation by 'off the record' conversations}

Given the specificity of my research object and the lack of a unique institutional entry to study it, I had to choose specific venues in order to achieve direct observation. The consequence was that I could only have a biased view on a grand corps because I could not access all of the institutions relevant to its functioning and public representation - that is, for example, the different ministries and private companies that members of one grand corps work for, the grand corps' professional association, their trade-unions, their main ministry's cabinet, local governments they sometimes represent, and so on. I had to find stopgap measures. One of these was the use of repeated interviews with the same people from different institutions, which enabled me to develop a relationship based on trust and to 'de-ritualise' the interview situation in order to access information that one can only usually gather after an immersion in the social world studied. After undertaking several interviews with the

\footnotetext{
${ }^{3}$ Compared to other pieces of research - and in particular in the US where some academics extensively state the difficulties they encountered and admit 20-minute-long interviews (Brown et al., 1990) - these interviews were purposefully longer than usual. The longest was carried out from the beginning of the afternoon to the evening, at the interviewee's office, and was uninterrupted. The exceptionally long interview can probably be explained by two reasons. The first one is that it was an 'interview on archives', there was therefore a paper format and much cross-checking, during which we were going back and forth between his memories and the facts, which were recorded in the written documents. The second reason is that after spending 4.5 hours speaking about the reform process, the interviewee was drawn into more personal questions about his social background, career, and connections.

${ }^{4}$ If there are no formal rules in that matter I thought it was preferable to raise more private issues regarding the individual itinerary of the interviewee at the very end of the interview. One can find different academic points of view on this matter. For example, Jean-Baptiste Legavre considers that encouraging an interviewee to speak about the path his/her life took at the very beginning of the interaction helps in easing the situation (Legavre, 1996, p.218). On the other hand, in my experience, it can be easier and more effective to try and depersonalize the interview from the start in order to reassure the interlocutor regarding my respect for his/her anonymity, and to wait for a climate of confidence to be created. Once I won his/her trust the interviewee was usually less on his/her guard and was more willing to speak about him/herself.
} 
same bureaucrats, I could sometimes meet them fairly informally - alone or, even better, accompanied by their colleagues - for a coffee in Saint-Germain-des-Près for example, next to the corps of roads and bridges professional association, or for lunch at their ministry's canteen. On these occasions I could either attend conversations related to the reforms I studied or engage in informal talks with the person I was meeting. These invaluable meetings took place in a very flexible way, outside 'rules of sociological method'. And I think it is precisely thanks to this 'freeing' that these informal conversations divulged rich information. Interactions were usually more relaxed, speech was less monitored, people talked more freely, and the informal setting generally encouraged 'connivance'. It was usually during these off the record moments that I managed to get important information, such as the mention of a name, the decoding of a specific standpoint one had taken, an interpretation of a conflict, and so forth. Of course, one has to be aware of the sociological conditions which may enable the easing of conversations on top of the contexts' informality. But the fact is that details which interviewees used to consider as 'scullery information' (insufficiently significant or respectable to be worth mentioning to outsiders) and were reluctant to give during interviews came up more naturally in this type of setting. Failing the possibility to record these verbal contributions, I would usually memorize a few key words linked to the main information collected. Once the person had left, the first thing I did was quickly jot down these key words in my fieldwork diary. Immediately after, I found it important to set aside time to then develop the ins and outs of the stories summarized by these words.

\section{When immersion impedes formal interviews: interviews in a conversational mode}

While I was engaged in direct observation of high civil servants, within their training, during their meetings, and in their more private gatherings, I was willing to obtain more information on specific points through the means of interviews. But in some cases it turned out to be more difficult than I had expected. This was partly the consequence of my situation, which was ambiguous both from a material and from a spatial point of view. I will discuss this point first before tackling the difficulties one can encounter when conducting interviews while carrying out direct observation.

My research was funded by a ministry, via one of the French corps' school and its centre for research in political science 5 . If members of a grand corps work in various public and private institutions, half of them usually work for a specific ministry, which is considered as the grand corps' mother institution. I was funded by the Ministry of Transportation, Equipment, Housing and Tourism, the umbrella ministry of the corps of Roads and Bridges. Fortunately the intervention of the ministry's people was limited to funding, so I was totally free to design my research question and fieldwork as I wanted. Being funded by a ministerial institution while studying its top bureaucrats may appear to be an asset. Access to people and documents may be eased, people may trust you more easily as they can identify you more clearly, it may break down some barriers, and so forth. But I made the decision not to reveal this information to the mandarins I met in the course of my research. Being interested in these bureaucrats' distance from their professional roles, the overlap of

\footnotetext{
${ }^{5}$ All the Grandes Ecoles have centres for research and the three Grandes Ecoles where technical high civil servants are trained host centres for research specializing in social sciences. For example, Bruno Latour was a researcher at the Ecole des Mines.
} 
their private and public interests, their detachment vis-à-vis their main ministry's policies, I assumed that I would learn more by putting forward my academic identity rather than revealing the details of my funding. Identifying me as an academic (rather than being seen as the ministry's eyes and ears) seemed to appear quite reassuring for these grands corps members, my position being, supposedly, non political and/or uncontroversial, and therefore quite harmless. My decision raises ethical issues regarding what researchers can hide to their interviewees or to what extent they can omit exposing every details of their situation. I made the hypothesis that revealing the financial links that I had with the ministry would introduce a bias in my research as it would encourage the interviewees to speak as (and only as) representatives of their ministry. I wagered that they would probably conceal some information and feel less confident in telling me about their strategies or the way they maybe shaped administrative reforms according to their grand corps' interests. And, indeed, I now believe I could never have brought to light the divergences between grands corps' positions and ministerial interests (most of the time defended by members of the grands corps themselves) if I had introduced myself as being funded by the ministry. It would probably have artificially homogenized high civil servants' positions, as if they uniformly embodied their ministry or even public interest itself. Some major information would probably have been concealed in the name of a convention (revealing the details of my funding), and I can see no reason why it would prevail over scientific interests.

From a spatial point of view, the ambiguity of my situation made it difficult for me to conduct interviews with people working in the Ecole where I was doing direct observation as well as teaching. I indeed had an office in an Ecole where civil servants were trained, and I was working among bureaucrats, some of whom were my fellow researcher colleagues. I therefore became acquainted with some of them or even struck up friendships. Even though these civil servants were not directly at the heart of my research (they worked with engineers of Roads and Bridges but were themselves engineers of public works, i.e. lower in the hierarchy), these professional and friendly relationships did not really lend themselves to this type of fieldwork exercise, which breaks the spontaneity of interactions and artificially formalizes exchanges. If they were well aware of the nature of my research and willing to engage in conversations on this topic, they were cautious of being interviewed formally. Leading interviews in this kind of situation happened to be even more problematic because the people involved were either academics or training to be, and were therefore even more aware of the researcher's intentions. But on top of this gap between informal relationships and the artificial formality of the interview situation, these people appeared to be reluctant to get involved in the power relations of the interview encounter. Indeed, some of these civil servants were engineers changing their careers and were shifting to social sciences by writing a $\mathrm{PhD}$. They found it hard to be 'reduced' to their 'engineer's identity', which for them was perceived to imply an unacceptable level of objectification. Thus my situation of immersion in part of the field I was studying led me to get round the 'Rules of Methods'. Consequently, I undertook several interviews with an indistinctive status in between semi-structured interviews and off the record conversations - which I have called 'interviews in a conversational mode'. They can be considered interviews insofar as they are structured according to a semi-standardized list of questions 
posed by a listening researcher, but they appear from outside as informal conversations with no recording or note-taking. This researcher's position had not been previously thought of as being a way to glean information. It appeared by trial and error as I went along in my fieldwork.

\section{'Interviews on archives'}

I would now like to deal with a research experience which happened to be very productive and speaks in favor of combining interviews and archives. These two methodological tools appear to be very complementary indeed. To begin with, conducting interviews may be an effective way to access archives, private collections, and documents that are internal to a specific institution. Furthermore, they can bring up more strategic and more political elements that are usually concealed in written documents. But what I found particularly interesting was the actual combination of the two techniques in 'interviews on archives'. From the high civil servants' point of view, it looks as if mobilizing archives gave the researcher the status of a historian, which seems to appear much more serious and legitimate than that of a sociologist or a political scientist carrying out interviews (Laurens, 2007). Moreover, the use of archives enables the interviewer to turn the conversation round to past practices and directs it towards facts, events, and decisions rather than timeless and idealistic speeches, and general points of view on broad issues. It also gives the researcher the opportunity to confront high civil servants' memories with written proof. Furthermore, the combination of both methods enabled me to couple together the advantages of the familiarity that I had with some high civil servants and the accuracy of the archives at my disposal, and thus I had the opportunity to benefit from long archive-deciphering sessions, in particular with the main architect of one of the NPM reforms at stake. By confronting written pieces and the account of a major witness to the reform, I was given the opportunity to make him react to some of my hypothesis and to listen to his justifications. Thus not only was it a way to obtain explanations on certain pieces of written documents or to seek for validation, but also it enabled me to witness his reactions to my analysis and interpretations. These long discussions enabled me to obtain information that I would never have accessed otherwise. Among other things, they helped me to put events back into order, understand shifts and reversals, decipher documents written in an elliptical style, and put summaries of conclusions which did not mention the debates and different stages they stemmed from back into context. In short, it enabled me to combine the materiality of written documents with the thickness and complexity of information available through interviews.

\section{$\underline{\text { Stopgap sources }}$}

Many meetings marking the rhythm of the reform process were not accessible to observation. The only traces I was left with were the written documents that they had led to in the archives. Faced with such an access issue, the researcher is forced to find tricks. I had the opportunity to come up with specific kinds of written documents which partly made up for this lack of an exhaustive perspective on the reform process. In addition to the available archives, I indeed had access to specific archives that I have called 'internal documents'. In one of the Ministry of 
Transportation, Equipment, Housing and Tourism's premises, located in La Défense near Paris, at the bend in the corridor of the human resources' department, one can find a small room that the ministry's employees enigmatically call 'the crypt'. Whereas the archives I had in my possession - either filed and referenced by an archivist or stored by an individual - were the result of a selection in which the researcher did not have any role, the 'internal documents' I found in 'the crypt' had not been subjected to any kind of filtering or any arrangement. The room was furnished with shelves on which were stored 'raw' files with numerous documents of all types, amassed in the course of the reform process and piled up with no apparent rationale (not even a chronological one). They seemed to be stacked as they were once the reform had been completed or after the bureaucrat in charge had left. These documents were not intended for the use of researchers - ministries usually have their own archives department - but were addressed to the leaving bureaucrat's possible successors or to any other civil servant from her/his department who might have been interested. Among these 'internal documents' I found, mixed together, reports, letters, press clippings, statistic tables, agendas, minutes, internal notes, tracts, decree drafts, summaries of conclusion, and so on. There were sometimes inexplicable 'silences', involving several months or even a year without documentary traces. On top of this, many documents were either not dated or only inaccurately so. I tried to date them approximately, as a jigsaw puzzle under construction that I completed as I went along. I was helped in this task by certain documents, among which were periodic summaries of the reforms at stake intended for the use of the minister who could keep track of the process by this means. Finding intermediate versions of decree drafts or of some administrative letters written in different steps helped me to place events in relation to one another. It also enabled me to see the actual making of the reform in its most microscopic and apparently irrelevant details, which sometimes turned out to be the most revealing.

From this same perspective I had the opportunity to discover quite by chance an incredibly rich source among the archives I found: the handwritten notes of a major actor in the relevant reforms. This high civil servant meticulously transcribed everything which was said in scrupulous and comprehensive detail during the meetings that he attended. Only occasionally was the handwriting completely illegible. People's verbal contributions and even their passing remarks were written down fully, below the name of the speaker. These handwritten notes played a part which was relatively similar to that of direct observation (though it was a second hand source) insofar as it helped me shed light on the gap between the dialogue during the meetings and their polite, official transcription in the minutes. The notes enabled me to read between the lines - they represent an interesting key in the analysis of the process of translation undergone by unpolished interventions, personal attacks, open hostility, or too-obvious innuendo. Beyond 'little stories' which may arouse the researcher's attention but may not be interesting from an analytical point of view, this kind of lively written document brings the debates into life and reintroduces the significance of more political and strategic elements.

The third type of original source I had the opportunity to work on was email correspondence, very fortunately printed by some top civil servants. These emails were usually internal to the ministry concerned and were exchanged between high civil servants with regard to the reforms analysed. They have been of primary 
importance for my research and I wager they have become essential for whoever is willing to study a reform process from its genesis to its implementation stage. The spread of the use of Internet in professional correspondence, in both formal and informal exchanges, have made these traces à rebours (Certeau, p.58) - loosely translatable as 'backwards traces' - essential for whoever wants to reconstruct decision-processes.

\section{Conclusion: context-sensitive fieldwork and its limits}

As far as the sociological study of an administrative reform process is concerned, immersion and direct observation appear as an ideal approach for three main reasons: i) they enable the researcher to witness on the spot the decision-making process as it unfolds in real time; ii) they make it easier to access more traditional written sources; and iii) they turn out to be helpful for gathering invaluable oral information, thanks to interpersonal exchanges and the establishment of trustful relationships. In expounding these points, the foregoing aims to show the merits of an approach that at times may appear to those preferring neat, predefined schemes as a form of empirical DIY. The point of this paper, when the very nature of the population under the microscope may reduce the range of available methods, is to suggest that combining methods in context-sensitive fieldwork 'in a responsive mode' also has claims on political science methodology.

Nonetheless, each of the solutions described above, like any methodology, has its own biases, defects, blind spots and vulnerabilities. For example, the use of 'interviews in a conversational mode' or of off the record contributions in a publication or any written work poses obvious ethical problems. Resorting to 'interviews on archives' and handwritten notes not only does not replace the advantages of direct observation but also makes the researcher dependent on one individual's subjective point of view. And, finally, if I was lucky to discover some of the emails exchanged during the reform process, one can presume that it is not a usual professional habit to keep a written and material trace of this type of communication in the administration and elsewhere. The spreading use of this means of communication and the transient and slippery nature of such a source may make it more and more difficult for the researcher to get hold of precious information in the understanding of a reform process or any decision-making within a closed group.

The difficulties described in this chapter are relatively common in qualitative fieldwork, and they are only made more salient here because of the professional and social rank of the actors studied, as well as the closed character of the elite in question. There are no perfect ways to guarantee the validity of a sociological study, but mixing methodological tools in a responsive and context-sensitive mode can limit the vulnerabilities attendant on single-method dependency, and overcome difficulties of access, while still defining methodological standards. 


\section{Bibliography}

ABERBACH Joel D., PUTNAM Robert D. and ROCKMAN Bert A., Bureaucrats and Politicians in Western democracies, London, Harvard University Press, 1981.

BECKER Howard S., Tricks of the Trade. How to think about your research while you're doing it, Chicago, University of Chicago Press, 1998.

BONGRAND Philippe and LABORIER Pascale, « L'entretien dans l'analyse des politiques publiques : un impensé méthodologique? », Revue française de science politique, vol.55, $\mathrm{n}^{\circ} 1$, February 2005, pp.73-111.

BOURDIEU Pierre, Sur l'Etat. Cours au Collège de France (1989-1992), Paris, Seuil, 2012.

BOURDIEU Pierre, «Esprits d'État. Genèse et structure du champ bureaucratique », Actes de la recherche en sciences sociales, $\mathrm{n}^{\circ}$ 96-97, March 1993, pp.49-62.

BROWN Lynn et al., "Interviewing Political Elites", Political Science and Politics, vol.23, $\mathrm{n}^{\circ} 3$, pp.451-455.

CHAMBOREDON Hélène et al., "S'imposer aux imposants: à propos de quelques obstacles rencontrés par des sociologues débutants dans la pratique et l'usage de l'entretien", Genèses, n¹6, 1994, pp.114-132.

DE CERTEAU Michel, L'écriture de l'histoire, Paris, Gallimard, 2002.

ELIAS Norbert, What is Sociology?, London, Hutchinson, 1978.

GERVAIS Julie, "Merging to survive? Institutional legitimacy and material considerations in the light of the reorganisation of corps within the French civil service", International Review of Administrative Sciences, vol.76, n³, September 2010, pp.425-441.

GERVAIS Julie, "The rise of managerialism as a result of bureaucratic strategies and power games", in EYMERI-DOUZANS Jean-Michel and PIERRE Jon (eds), Administrative Reforms, Democratic Governance and the Quality of Government, Routledge, 2011, pp.8093.

LAURENS Sylvain, "Pourquoi" et "comment" poser les questions qui fâchent? Réflexions sur les dilemmes récurrents que posent les entretiens avec des "imposants" », Genèses, n69, April 2007, pp.112-127.

LEGAVRE Jean-Baptiste, «La "neutralité" dans l'entretien de recherche. Retour personnel sur une évidence », Politix, vol.9, n³5, 1996, pp.207-225.

LOWI Ted J., "The State in Politics: The Relation between Policy and Administration", in NOLL Roger G. (ed.), Regulatory Policy and the Social Sciences, California, University of California Press, 1985, pp.65-105.

OSBORNE David and GAEBLER Ted, Reinventing Government. How the Entrepreneurial Spirit is Transforming the Public Sector, Reading, MA, Addison-Wesley, 1992.

PAGE Edward C., « The civil servant as legislator: law making in British administration », Public administration, vol.81, $\mathrm{n}^{\circ} 4,2003$, pp.651-679.

PAGE Edward C. and JENKINS Bill, Policy Bureaucracy: Government with a Cast of Thousands, Oxford, Oxford University Press, 2005. 
PAGE Edward C. and WRIGHT Vincent (eds), Bureaucratic Elites in Western European States: a Comparative Analysis of Top Officials in Eleven Countries, Oxford, Oxford University Press, 1999.

PAGE Edward C. and WRIGHT Vincent (eds), From the Active to the Enabling State. The Changing Role of Top Officials in European Nations, Basingstoke, Palgrave Macmillan, 2007.

PINCON Michel and PINCON-CHARLOT Monique, "Pratiques d'enquête dans l'aristocratie et la grande bourgeoisie: distance sociale et conditions spécifiques de l'entretien semi-directif', Genèses, n¹4, pp.120-138, 1991.

SULEIMAN Ezra, Elites in French Society: the politics of survival, Princeton, Princeton University press, 1978. 